\title{
Obturator Foramen
}

National Cancer Institute

\section{Source}

National Cancer Institute. Obturator Foramen. NCI Thesaurus. Code C75332.

An opening in the hip bone formed by the public bone and the ischium and closed by the obturator membrane. 